\title{
Quality Benchmarking in Trauma: from the NTDB to TQIP
}

\author{
Melissa A. Hornor ${ }^{1,2} \cdot$ Christopher Hoeft $^{3}$ - Avery B. Nathens ${ }^{1,3,4,5,6,7}$ \\ Published online: 20 April 2018 \\ (C) Springer International Publishing AG, part of Springer Nature 2018
}

\begin{abstract}
Purpose of Review This review describes the evolution of quality improvement in trauma from the creation of the Committee on Trauma's (COT) Optimal Hospital Resources for Care of the Injured Patient in 1976 to the National Trauma DataBank (NTDB) to the American College of Surgeons' (ACS) Trauma Quality Improvement Program (TQIP).

Recent Findings The national standardization of data collection for trauma patients through the National Trauma Data Standard (NTDS) and TQIP has allowed trauma centers to benchmark with their peers and focus quality improvement initiatives on areas of opportunity. TQIP provides enrolled hospitals with the data and educational resources they need to improve trauma care.

Summary This review describes the development of ACS TQIP and quality benchmarking in trauma. The ACS COT began its journey to improve the quality of trauma care by establishing standards for the optimal care of injured patients and verifying that centers had the necessary equipment, personnel, and processes in place. The standardization of data collection for seriously injured patients nationally now has allowed trauma centers to meaningfully measure patient outcomes. ACS TQIP has further advanced trauma care by providing participating centers with the resources they need to achieve quality improvement in trauma.
\end{abstract}

Keywords Injury $\cdot$ Trauma $\cdot$ Registry $\cdot$ Data $\cdot$ Benchmarking $\cdot$ Quality improvement

\section{Introduction}

The care of injured civilians has progressed dramatically since the American College of Surgeons' (ACS) Committee on Trauma (COT) first published Optimal Hospital Resources for Care of the Injured Patient in 1976 [1]. This seminal publication prescribed for the first time the equipment, personnel, and infrastructure hospitals needed to provide high-quality trauma care. It has since been re-titled Resources for the

This article is part of the Topical Collection on Patient Safety and Quality in Trauma

\section{Avery B. Nathens}

anathens@facs.org

Melissa A. Hornor

mhornor@facs.org

Christopher Hoeft

choeft@facs.org

1 Division of Research and Optimal Patient Care, American College of Surgeons, Chicago, IL, USA

2 Department of Surgery, The Ohio State University College of Medicine, Columbus, OH, USA
Optimal Care of the Injured Patient and undergone several revisions with an associated increase in survival rates due to injury. Despite this progress, trauma remains an important and underestimated cause of morbidity and mortality. Fatal injuries account for $59 \%$ of all deaths among persons aged $1-44$, and those that survive often suffer significant mental, physical, and financial consequences [2]. Quality improvement (QI) in trauma care remains relevant and necessary. This review describes the creation of the ACS' Trauma Quality Improvement
3 Trauma Quality Improvement Program, American College of Surgeons, Chicago, IL, USA

4 Sunnybrook Research Institute, Toronto, Canada

5 Sunnybrook Health Sciences Center, Toronto, Ontario, Canada

6 Department of Surgery, University of Toronto, Toronto, Ontario, Canada

7 Division of General Surgery, University of Toronto, Toronto, Ontario, Canada 
Program (TQIP), a quality program that allows trauma centers to externally benchmark their performance and provides the tools to improve trauma outcomes.

\section{The History of Trauma Quality Improvement}

In 1987, after defining the skills and equipment trauma clinicians and centers needed to provide quality care, the ACS COT then established the Verification Review Consultation (VRC) program. This program was designed to evaluate whether a center adequately meets the criteria described in the COT's resource manual for the purpose of trauma center verification and/or consultation. The VRC provides the public assurance that verified centers meet the criteria required for the anticipated level of trauma care they are to deliver (levels I, II, III, IV and pediatric). When necessary, through its consultation mechanism, the VRC assists trauma centers in meeting standards needed to provide optimal care.

In parallel with the VRC, regional (e.g., state) health authorities often used these levels of verification to designate trauma centers and organize trauma systems on a regional level [3]. Consequently, the ACS COT's systematic approach to trauma care created a regionally organized system of care for injured patients. The organized system ensured that injured patients would receive adequate treatment, no matter their geographic location. Triage protocols were implemented, staffing improved, protocols matured, transfer policies changed, and ultimately injury-related mortality steadily declined [4-6].

One verification requirement for level I and II trauma centers was the collection of patient data through a trauma registry. The first such registry was developed and implemented at Cook County Hospital in 1973 [7], and beginning in 1986, this became an essential element as prescribed by the COT's resource manual. The ability to measure processes of care and outcomes set the stage for local performance improvement initiatives that led to further reductions in mortality and morbidity [8].

However, performance improvement opportunities are limited when the sole focus is internal. A review of outcomes, sentinel events, and selected processes of care from year to year assures consistency (or stability) but does not answer the question "are we as good as we can be?" The first opportunity to answer this question came through the development of the Trauma Score and Injury Severity Score (TRISS). TRISS allowed centers to identify patients with unexpected mortality outcomes based on their probability of survival as estimated by a statistical model [9]. TRISS provided estimates of the expected numbers of survivors by using a regression model defined by age $(\leq 54,>54)$, mechanism of injury (blunt vs penetrating), Injury Severity Score (ISS), and the Revised Trauma Score (the Glasgow Coma Scale, systolic blood pressure, and respiratory rate). Being the first of its kind, the TRISS method was revolutionary, but became obsolete as the regression coefficients from the model were estimated from data obtained from a single point in time - the Major Trauma Outcomes Study — where data were collected over 1982-1987 [10]. In effect, estimates of predicted rates of survival would be fixed in time - care today would be compared to predicted outcomes from the 1980s. Also, many argued that the TRISS method did not adequately account for patient case mix. As an example, most would concede that a 55-year-old and a 90year-old with the same injuries have dramatically different probabilities of death.

\section{Achieving the Ability to Externally Benchmark Trauma Outcomes}

The ACS COT looked internally when developing a riskadjustment method that would move beyond TRISS. The ACS' National Surgical Quality Improvement Program (NSQIP), created in 1994, allowed centers to externally benchmark their surgical outcomes using standardized, highquality clinically abstracted data coupled with validated riskadjustment statistical methodologies. Through ACS NSQIP's semi-annual report, each hospital received a ratio of riskadjusted observed-to-expected (O/E) predictions for hundreds of outcomes relevant to surgery (e.g., death, cardiac events, infections, unplanned intubation, renal failure, pulmonary embolism, length of stay, return to operating room) [11]. These detailed reports allowed hospitals to identify areas of low performance compared to peers and target quality improvement efforts on those problem areas. ACS NSQIP facilitated collaboration between hospitals, allowing low-performing centers to gain insight on best practices utilized by high-performing centers. ACS NSQIP-enrolled centers demonstrated improvement in outcomes, the magnitude of which increased with time enrolled in the program [12], further evidence that external benchmarking took quality improvement to a higher level.

\section{Standardizing Trauma Data Through the National Trauma Data Standard}

While ACS NSQIP was designed as an external benchmarking program from its initiation with standardized data collection and a single registry at its core, ACS TQIP evolved quite differently. Trauma centers already had their own registries that were suited to local needs [7]; centers used variable inclusion criteria, used non-standardized definitions for data fields, and had varied approaches to injury severity coding [13]. Further, registrars had no standardized training for data abstraction. Each registry evolved in divergent ways, assuring a lack of consistency and standardization. However, 
data were already being aggregated at the national level by the ACS through the National Trauma Data Bank (NTDB), which set the stage for ACS TQIP. In 2007, the National Trauma Data Standard (NTDS) was created through a consensus of multiple stakeholders [14]. The NTDS specified which fields needed to be collected, the field structure, and how the field is defined, and provided a source hierarchy indicating where the fields should be captured from the medical record. The NTDS allowed the evolution of NTDB into the core data holding for ACS TQIP as it allowed for data to be compared across trauma centers.

\section{Putting it All Together: ACS TQIP}

The ACS has a long history of surgical quality improvement collaboratives built upon four main pillars: (1) set the standards for the best care, (2) build the right infrastructure needed for care, (3) collect standardized data, and (4) verify through a third party to establish public assurance. The standardization of NTDB data through NTDS allowed for the addition of outcome assessment to the verification program that to this point had focused only on ensuring adequate structures and processes to care for the injured patient. Additionally, comparative benchmarking allowed for the evolution of trauma centers' performance improvement programs. Together, this created the impetus for the creation of a quality improvement program in trauma.

Further evidence for a need for such a program came from work by Shafi and colleagues who utilized NTDB data to compare risk-adjusted outcomes among 58 ACS VRC verified level I trauma centers. Although the VRC verified that each center had the optimal structures and processes in place as defined by the Resources for the Optimal Care of the Injured Patient, their mortality outcomes were highly variable; almost $25 \%$ of centers had a higher than expected rate of death and $19 \%$ of centers had mortality rates lower than expected based on their case mix [15••]. It appeared that there was further opportunity to improve the care of injured patients, above and beyond the VRC trauma accreditation process

In 2006, the chairman of the ACS COT, John Fildes, MD, FACS, convened a work group lead by Gill Cryer, MD, FACS, to create and implement a quality improvement program for trauma. The vision was to create a program that would allow centers to compare risk-adjusted outcomes with their peers. This would provide direction to centers as to where they need to focus their QI efforts, beyond deficiencies they could identify on an internal basis. It would also identify high-performing centers who might share their practices with the trauma community, thus elevating the quality of trauma care across the USA. A pilot study was conducted in 20082009 that verified the feasibility of TQIP as a collaborative quality improvement program by using risk-adjusted data to benchmark 23 trauma centers. The results were distributed to the participating centers through a data report that the participants found to be clear, useful, and actionable [16].

TQIP has grown tremendously since it first enrolled 23 level I and II trauma centers in the pilot program, with 467 hospitals enrolled. Pediatric TQIP was launched in 2014 and now has 127 sites enrolled. The program was recently extended to include level III sites, and as of early 2018, has 139 sites enrolled. Overall, TQIP hospitals are present in all 50 states and Washington D.C. and several countries and have over 750 participating trauma centers (Tables 1 and 2).

\section{Statistical Analysis and Data Reports}

ACS NSQIP has allowed hospitals to improve outcomes for surgical patients nationwide [12], but would this same structure work for the trauma population? ACS NSQIP performs risk adjustment by including approximately 45 standard predictors, ranging from laboratory values to comorbid conditions. It includes hundreds of outcome models for surgical complications, including outcome models for specific procedures like colectomy and pancreatectomy [11]. The trauma patient population, however, is extremely different from the

Table 1 Characteristics of level I and II trauma centers participating in TQIP $(n=467)$ for hospitals included in the Fall 2017 Reporting Cycle

\begin{tabular}{lcc}
\hline Hospital characteristics & Number & Percent \\
\hline Trauma level & & \\
I & 201 & 43 \\
II & 266 & 57 \\
Bed size, $n$ & & \\
$<200$ & 31 & 7 \\
201-400 & 162 & 35 \\
$401-600$ & 135 & 29 \\
$>600$ & 139 & 30 \\
Teaching type & & \\
University & 174 & 37 \\
Community teaching & 211 & 45 \\
Community nonteaching & 82 & 18 \\
Hospital type & & \\
For profit & 62 & 13 \\
Nonprofit & 405 & 87 \\
Geographical region & & 21 \\
International & 7 & 25 \\
Northeast & 98 & 30 \\
Midwest & 118 & \\
South & 139 & \\
West & 105 & \\
\hline
\end{tabular}


Table 2 Pediatric TQIP hospital characteristics $(n=127)$ for hospitals included in the Fall 2017 Reporting Cycle

\begin{tabular}{|c|c|c|}
\hline Hospital characteristics & Number & Percent \\
\hline \multicolumn{3}{|l|}{ Trauma level } \\
\hline I & 46 & 36 \\
\hline II & 66 & 52 \\
\hline None & 15 & 12 \\
\hline \multicolumn{3}{|l|}{ Hospital status } \\
\hline Adult/pediatric combined & 85 & 67 \\
\hline Pediatric only & 42 & 33 \\
\hline \multicolumn{3}{|l|}{ Bed size, $n$} \\
\hline$<200$ & 9 & 7 \\
\hline $201-400$ & 36 & 28 \\
\hline $401-600$ & 36 & 28 \\
\hline$>600$ & 46 & 36 \\
\hline \multicolumn{3}{|l|}{ Teaching type } \\
\hline University & 83 & 65 \\
\hline Community teaching & 39 & 31 \\
\hline Community nonteaching & 5 & 4 \\
\hline \multicolumn{3}{|l|}{ Hospital type } \\
\hline For profit & 8 & 6 \\
\hline Nonprofit & 119 & 94 \\
\hline \multicolumn{3}{|l|}{ Geographical region } \\
\hline Northeast & 31 & 24 \\
\hline Midwest & 37 & 29 \\
\hline South & 38 & 30 \\
\hline West & 21 & 17 \\
\hline
\end{tabular}

rest of the surgical population, and the data registry needed to meaningfully measure and improve outcomes is different as well.

To determine which NSQIP data elements were most important to collect within the trauma population, Hemmila and associates analyzed outcomes from a cohort of 525 trauma patients using NSQIP data principles [17•]. Their findings revealed that trauma patients have less comorbid conditions than NSQIP patients, and their comorbidities are not as important for risk adjustment. Similarly, laboratory parameters were not as important in trauma patient models. Trauma patients, in general, are young and healthy before injury, so may require fewer data elements for risk adjustment. Conversely, complication rates were significantly higher within the trauma population. This confirmed the need for a data registry and statistical analysis methodologies specifically suited for trauma patients.

The NTDB registry included any patient admitted or transferred to the center with at least one injury (excluding late effects of injury, foreign bodies, and superficial injuries) [18]. On an institutional level, inclusion criteria were significantly variable specifically in relation to the duration of time that constitutes an "admission," whether dead on arrival patients were included, and whether isolated hip fractures in the elderly were included [13]. In response, the TQIP data registry included patients with an injury severity threshold high enough to capture a population common to all trauma registries (Table 3 ).

The NTDS contained most of the necessary data fields for risk adjustment, including patient demographics, comorbid conditions, initial physiology upon presentation to the emergency department (ED), transfer status, mechanism of injury, abbreviated injury scale (AIS) scores, and derived injury severity measures based on AIS-based survival risk ratios, which provide take into consideration the risk of adverse outcomes associated with each of the three worst injuries per patient [19]. These fields were incorporated into riskadjustment models to estimate risks of major complications and in-hospital mortality (Tables 4 and 5).

There were many potential methodologies to consider to increase the validity of the statistical models [20]. Ultimately, TQIP statisticians used hierarchical linear models (HLM) to create the risk-adjusted outcome models used in TQIP data reports. HLM is a statistical method that separately accounts for the differences between patients and the differences between trauma centers, since patients are not randomly assigned to TQIP hospitals. The HLM method produces odds ratios (OR) as a metric of hospital performance. If a center's OR for an outcome is greater than 1, then the odds of an event in that hospital are higher than average, and an OR less than 1 indicates that the odds of an event are lower than average. The TQIP data reports display outcomes with modified box plot charts, where the individual hospital's outcome estimate and confidence interval are shown in comparison with the entire TQIP sample (Fig. 1). Generally speaking, the lower the decile, the better the hospitals' outcomes are compared to other hospitals.

In keeping with ACS COT's philosophy that the foundation for quality care is having the optimal processes and

Table 3 TQIP inclusion criteria

- Age $\geq 16$

- At least 1 valid trauma diagnosis code

- Blunt or penetrating mechanism of injury, derived from submitted from International Classification of Diseases, 10th Revision (ICD-10) External Cause Code

- Abbreviated injury scale (AIS) score $\geq 3$ in at least one body region (pediatric and level III TQIP includes AIS $\geq 2$ )

- Non-missing values for emergency department and hospital discharge dispositions

- Exclusion criteria:

- Pre-existing advanced directive to withhold life-sustaining care

- Severe burns

- Patients with no signs of life on arrival

- Elderly patients (65 years or older) with an isolated hip fracture 
Table 4 Elements included in trauma quality improvement program risk-adjusted models

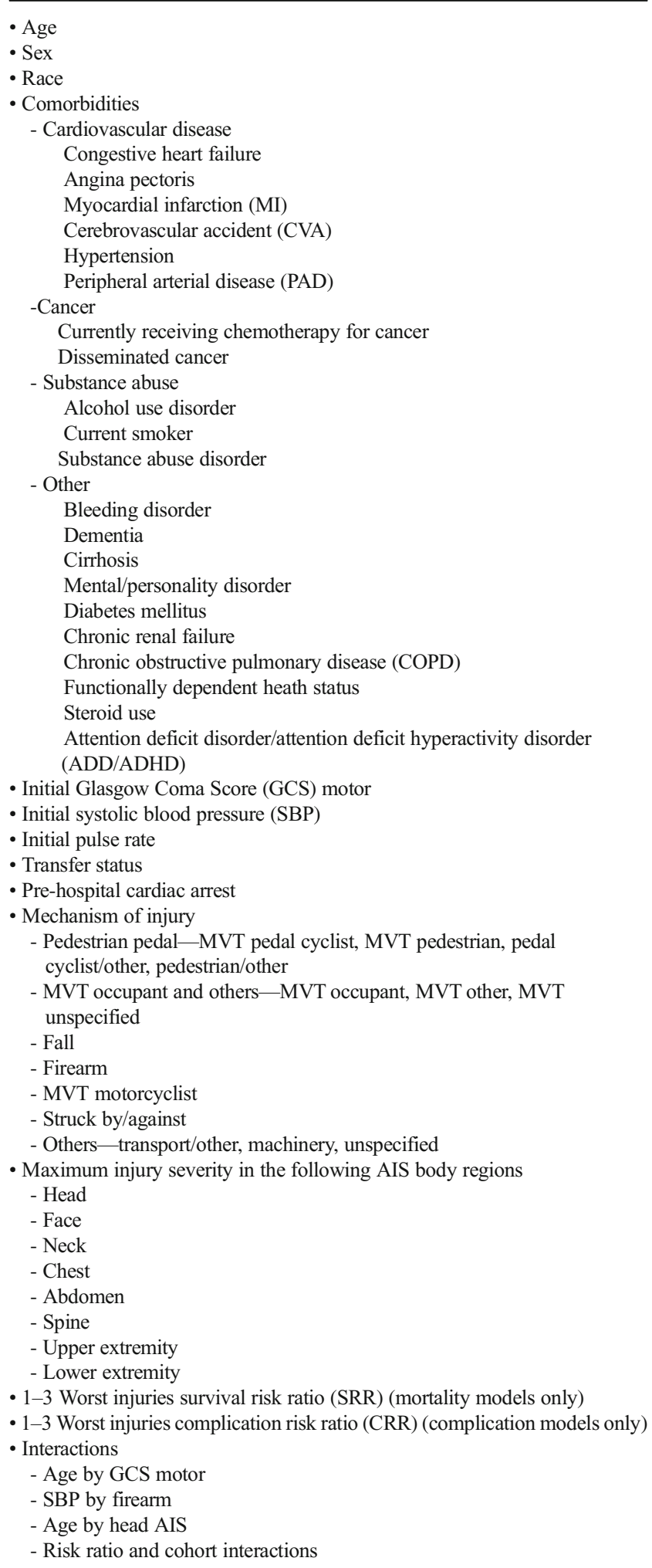

Table 5 Risk-adjusted outcomes included in TQIP data reports

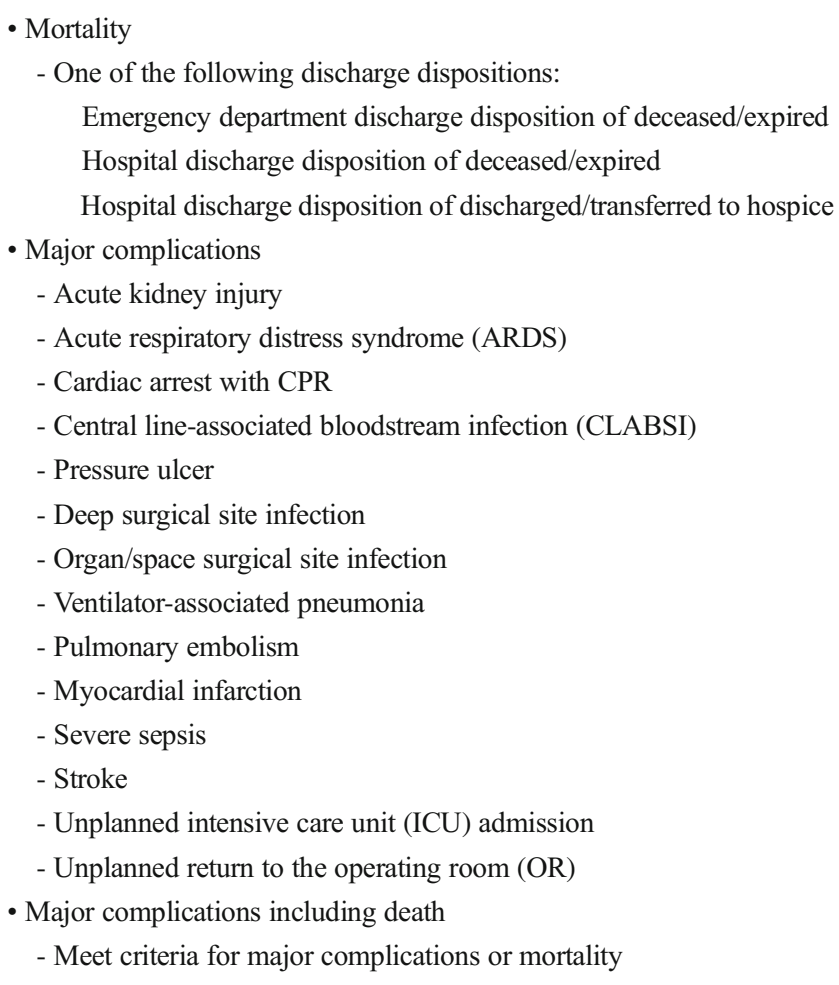

structures in place, TQIP reports on several processes of care metrics specific to trauma care. For example, the timely administration of venous thromboembolism (VTE) prophylaxis prevents adverse outcomes like deep venous thrombosis (DVT), pulmonary embolism, postthrombotic syndrome, and bleeding complications that result from prolonged therapeutic anticoagulation. Not all trauma patients are appropriate candidates for VTE prophylaxis, like those with ongoing hemorrhage, and the registry accounts for exceptions when necessary and applicable. Other TQIP process of care measures includes intracranial pressure monitoring in traumatic brain injury, timing of tracheostomy, timing of hemorrhage control, and time to operative fixation in patients with extremity fractures.

TQIP benchmarking reports provide risk-adjusted outcomes for all patients as well as for patient subsets according to patient or injury characteristics (Table 6). These groups allow centers to evaluate different aspects of trauma care like multidisciplinary care coordination, resuscitation strategies, resource use, and the timing of treatment. This approach acknowledges the heterogeneity inherent in a population of trauma patients and allows centers to focus QI on patients with specific attributes rather than on their entire admitted population. 


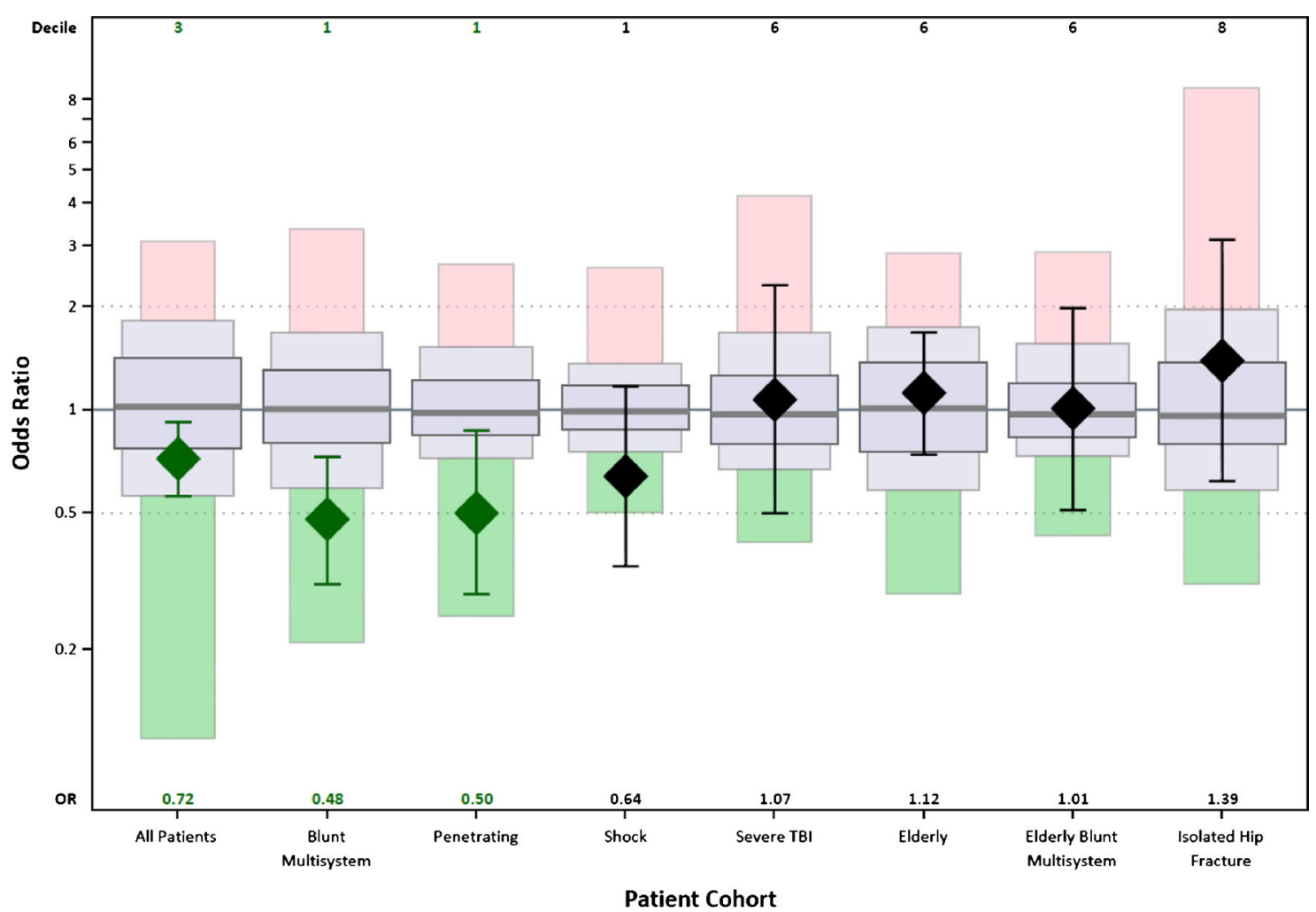

Modified boxplot displaying a sample hospital's risk-adjusted mortality by cohort. This sample hospital is a low outlier, or good performer, in the All Patient, Blunt Multisystem, and Penetrating cohorts, but is an average performer in the remaining cohorts.

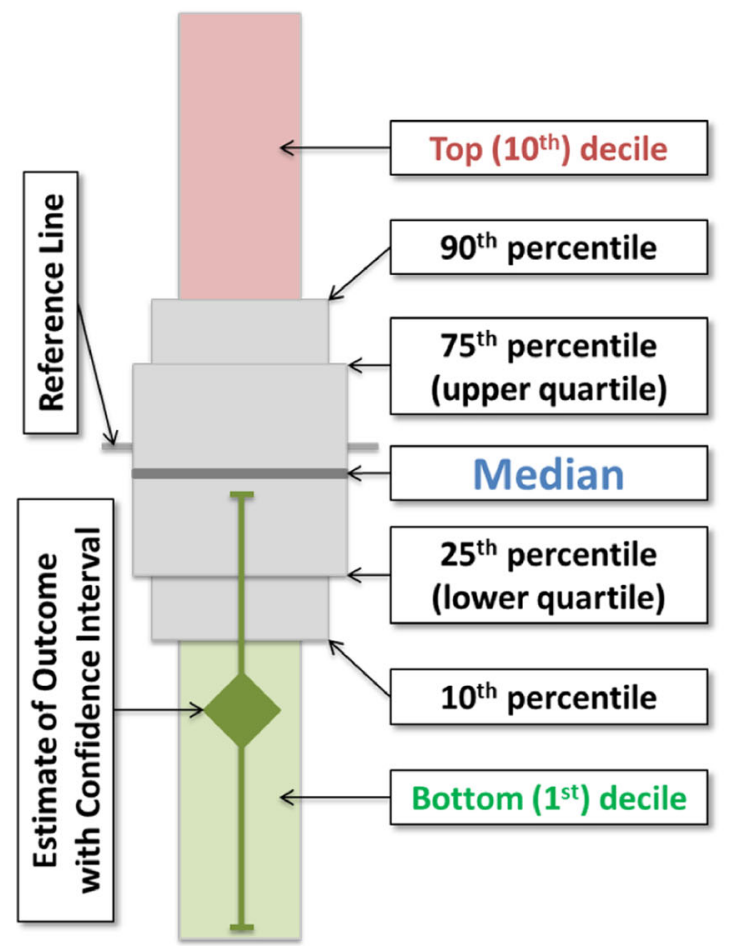

Box Decile Legend. 
Fig. 1 TQIP risk-adjusted mortality modified boxplot. Modified boxplot displaying a sample hospital's risk-adjusted mortality by cohort. This sample hospital is a low outlier, or good performer, in the all patient, blunt multisystem, and penetrating cohorts, but is an average performer in the remaining cohorts. Box decile legend

\section{Education and Training}

To achieve meaningful quality improvement, the trauma data registry must accurately reflect the care patients receive. TQIP includes several mechanisms that assure consistent, highquality data collection. These mechanisms include training courses and continuing education for trauma registrars through regular webinars, interactive question and answer sessions, quizzes, an annual online course, data logic checks, assessment of outlier values, internal validation to verify the appropriateness and completeness of data, and, where necessary, external data validation on site visits [21••]. On site visits, surveyors assess participating hospitals' processes for case identification, data abstraction, data entry, and data quality.

To help hospitals improve, TQIP provides performance improvement education and facilitates between-center collaboration on best practices. TQIP provides educational resources for trauma program managers and trauma medical directors that help them get the most out of benchmark reports, specifically how to "drill down" on problem areas and identify concrete processes or structures in need of improvement.
Table 6 TQIP patient cohort definitions

\begin{tabular}{|c|c|}
\hline TQIP patient cohort & Definition \\
\hline TQIP population (all patients) & $\begin{array}{l}\text { - Meet TQIP inclusion/exclusion criteria and do not qualify for elderly } \\
\text { isolated hip fracture cohort }\end{array}$ \\
\hline Blunt multisystem injuries & $\begin{array}{l}\text { - Blunt trauma type, derived from submitted External Cause Code } \\
\text { - Injury with AIS severity } 3 \text { or greater in at least } 2 \text { of the following body } \\
\text { regions: head, face, neck, thorax, abdomen, spine, upper, or lower } \\
\text { extremity }\end{array}$ \\
\hline Elderly patients & - Age $\geq 65$ \\
\hline $\begin{array}{l}\text { Elderly patients with blunt } \\
\text { multisystem injuries }\end{array}$ & - Age $\geq 65$ and meet cohort criteria for blunt multisystem injury \\
\hline $\begin{array}{l}\text { Elderly patients with isolated hip } \\
\text { fracture }\end{array}$ & $\begin{array}{l}\text { - Age } \geq 65 \\
\text { - Injury mechanism of fall, derived from submitted External Cause Code } \\
\text { - At least one of the AIS } 05 / 08 \text { codes listed in TQIP Reporting Code Sets } \\
\text { - Any other injuries are in AIS external body region (i.e., bruise, abrasion, } \\
\text { or laceration) }\end{array}$ \\
\hline Penetrating injuries & $\begin{array}{l}\text { - Injury mechanism of cut/pierce or firearm, derived from submitted } \\
\text { External Cause Code } \\
\text { - Injury with AIS severity }>3 \text { in at least one of the following body } \\
\text { regions: neck, thorax, or abdomen }\end{array}$ \\
\hline $\begin{array}{l}\text { Fractures (mid-shaft femur and } \\
\text { open/closed tibia shaft) }\end{array}$ & $\begin{array}{l}\text { - Blunt trauma type, derived from submitted External Cause Code } \\
\text { - ICD diagnosis code consistent with mid-shaft femur or open/closed } \\
\text { tibia shaft fracture }\end{array}$ \\
\hline Shock patients & - Initial ED/hospital SBP between 0 and $90 \mathrm{mmHg}$ \\
\hline Hemorrhagic shock patients & $\begin{array}{l}\text { - Initial ED/hospital SBP between } 0 \text { and } 90 \mathrm{mmHg} \text { Received } \\
\text { - Transfusion blood }>0 \text { within } 4 \mathrm{~h}\end{array}$ \\
\hline $\begin{array}{l}\text { Severe traumatic brain injury (TBI) } \\
\text { patients }\end{array}$ & $\begin{array}{l}\text { - Initial ED/hospital GCS Total } 8 \text { or less } \\
\text { - AIS severity } 3 \text { or greater for a valid qualifying injury in the AIS head } \\
\text { body region } \\
\text { - Patients are eligible for this cohort if they have another qualifying injury } \\
\text { (i.e., if they have a brain injury AND a code above, they may qualify } \\
\text { for the cohort) } \\
\text { - No other injuries with an AIS severity of greater than } 2 \text { in any other } \\
\text { non-head AIS body region (this criterion is not applied for the pediatric } \\
\text { or level III programs) }\end{array}$ \\
\hline Blunt splenic injuries & $\begin{array}{l}\text { - Blunt trauma type, derived from submitted External Cause Code } \\
\text { - At least one of the AIS } 98 \text { injury codes listed in TQIP Reporting Code } \\
\text { Sets }\end{array}$ \\
\hline
\end{tabular}


Quality improvement collaboratives are groups of hospitals within a specific geographic area or hospital system that work together to achieve a shared goal of trauma system quality improvement [17•]. There is strong evidence that collaboratives accelerate QI. In 2008, Guillamondegui and colleagues assembled a ten-hospital collaborative in Tennessee. The Tennessee collaborative provided a mechanism to share and discuss opportunities for improvement identified by NSQIP data. After 1 year, the Tennessee collaborative found improvements in surgical site infections $(-19 \%, P=0.0005)$, graft/ prosthesis/flap failure $(-60 \%, P<0.0001)$, acute renal failure $(-25 \%, P=0.023)$, and wound disruption $(-34 \%, P=$ $0.011)$. Collaborative quality improvement has also been shown to improve the quality of trauma care that centers provide. For example, trauma centers enrolled in the Michigan TQIP collaborative (MTQIP), saw a $40 \%$ decline in their serious complication rate from 2008 to 2013 (14.9 vs 9.1\%; $P<0.001$ ), and decreased mortality rates from $4.9 \%$ in 2010 to $4.1 \%$ in $2015[17 \cdot, 22]$.

TQIP has a collaborative program that includes 13 trauma center collaboratives derived from states, hospital systems, or COT regions. The TQIP collaborative program provides risk-adjusted reports that allow centers within a collaborative to benchmark with each other, and provides the collaborative an opportunity to benchmark its performance with the entire TQIP participant pool. The result is typically (i) a collaborative-wide effort to improve quality in one domain and/or (ii) centers within a collaborative share best practices to elevate the quality of care across all participating centers.

The TQIP Annual Scientific Meeting has been a valuable educational resource for centers since TQIP's launch in 2010. The TQIP Annual Scientific Meeting brings together trauma medical directors, program managers, coordinators, and registrars from participating centers and prospective TQIP hospitals. The conference focuses on educating centers on how they can use the program to improve care. Sessions address data quality, how best to interpret and use the report, and how to implement changes in practice that lead to improved outcomes. In addition to individual educational opportunities tailored to each role in the trauma program, there are collaborative exercises that bring surgeons, managers, coordinators, and registrars together to learn from each other.

\section{How Has TQIP Improved Care So Far?}

Data derived from TQIP has been used to take advantage of the variation in practices across centers to determine which practices are associated with optimal outcomes. This approach has been used to evaluate a number of practices across several specialties caring for severely injured patients. Several examples follow.

The optimal timing of femoral shaft fracture fixation was investigated using ACS TQIP data, leading investigators to conclude that hospitals that employ early fixation achieve superior patient outcomes. Byrne and colleagues performed a retrospective cohort study using ACS TQIP data from 216 centers and found that significant practice variability existed in delayed fixation of femoral shaft fractures even after controlling for patient and injury factors. Patients treated at centers where delayed fixation (defined as fixation greater than $24 \mathrm{~h}$ after hospital admission) was predominantly employed were at increased risk for pulmonary embolism (2.6 vs $1.3 \%$; rate ratio $[\mathrm{RR}] 2.0 ; 95 \% \mathrm{CI} 1.2-3.2 ; P=0.005)$ and prolonged length of stay (7 vs 6 days; RR 1.15; 95\% CI 1.1-1.19; $P<0.001)$ [23].

ACS TQIP was utilized to investigate the utilization of intracranial pressure (ICP) monitoring in traumatic brain injury (TBI) patients by Alali et al. [24]. The authors investigated the relationship between ICP monitoring and mortality in participating TQIP centers and found that on a hospital level, higher ICP monitoring utilization rates were associated with lower mortality, even after adjusting for case mix.

Benjamin and colleagues utilized ACS TQIP data to determine the optimal form of venous thromboembolism (VTE) prophylaxis in severe TBI patients. The investigators analyzed 20,417 TBI patients, 10,018 (49.0\%) of which received low molecular weight heparin (LMWH), and 10,399 (50.9\%) received unfractionated heparin (UH) for VTE prophylaxis. A multivariate analysis revealed that $\mathrm{UH}$ was associated with higher mortality (odds ratio [OR] 1.750, CI 95\% 1.504-2.035, $P<0.001$ ) and thromboembolic complications (OR 1.256, CI 95\% 1.094-1.442, $P<0.001)$ when compared to LMWH [25].

Finally, TQIP data can also be used to investigate the effectiveness of treatments for specific injured populations. Scarborough and associates investigated whether nonoperative treatment was effective in high-grade blunt splenic injuries, a treatment already well established in patients with lowgrade injuries. Two thousand seven hundred forty-six patients with high-grade blunt splenic injuries were identified within ACS TQIP, and outcomes were compared between those managed with immediate splenectomy versus nonoperative management. In-hospital mortality was not significantly different between the two management strategies (11.5 vs $10.0 \%$, $P<0.33$ ), and patients managed with immediate splenectomy had a higher incidence of infection complications (21.4 vs $16.9 \%, P<0.02)$. The presence of a bleeding disorder (OR 3.45; 95\% CI 1.85-6.43; $P<0.001)$, early blood transfusion (OR 2.37; 95\% CI 1.47-3.81; $P<0.001$ ), and grade $\mathrm{V}$ injury (OR 2.15; 95\% CI 1.47-3.15; $P<0.001$ ) were 
identified as independent predictors of failure of nonoperative management [26].

\section{The Future of TQIP}

A new data collection platform was recently launched in July 2017 for all American College of Surgeons' Quality Programs, including trauma. The new platform advances data collection and validation processes and will improve the available business intelligence tools, enabling participants to make better use of the program. The platform will also serve as the data infrastructure for interventional trials and will affect reimbursement through simplification of data submission for performance measures to CMS through the Surgeon Specific Registry [27].

The trauma verification program (VRC) was developed several years prior to TQIP's inception. Currently, efforts are underway to completely integrate TQIP with VRC. This integration will streamline the verification process for TQIP hospitals and will allow further investigation into the association of compliance with standards within the Resources for the Optimal Care of the Trauma Patient and risk-adjusted patient outcomes.

\section{Conclusion}

TQIP was made possible through the ACS COT's resolute commitment to improving trauma care over many decades. TQIP fosters national quality improvement in trauma by allowing for risk-adjusted benchmarking between trauma centers. TQIP data reports allow hospitals to identify areas of low performance, and collaborative communication structures allow trauma centers to communicate and share best practices. TQIP provides all of the tools a trauma center needs to reduce variability in trauma care, complications, and resource use and to improve survival. The TQIP data registry also serves as a valuable resource for comparative effectiveness research and the identification of national trends, which will help improve trauma care for the entire population.

\section{Compliance with Ethical Standards}

Conflict of Interest The authors declare no conflicts of interest relevant to this manuscript.

Human and Animal Rights and Informed Consent This article does not contain any studies with human or animal subjects performed by any of the authors.

\section{References}

Papers of particular interest, published recently, have been highlighted as:

- Of importance

- Of major importance

1. Optimal hospital resources for care of the seriously injured. Bull Am Coll Surg. 1976;61(9):15-22.

2. Centers for Disease Control and Prevention. Web-based Injury Statistics Query and Reporting System (WISQARS) [Online]. (2003). National Center for Injury Prevention and Control, Centers for Disease Control and Prevention (producer). Available from: www.cdc.gov/ncipc/wisqars. Accessed January, 2018.

3. MacKenzie EJ, Hoyt DB, Sacra JC, Jurkovich GJ, Carlini AR, Teitelbaum SD, et al. National inventory of hospital trauma centers. JAMA. 2003;289(12):1515-22.

4. DiRusso S, Holly C, Kamath R, Cuff S, Sullivan T, Scharf H, et al. Preparation and achievement of American College of Surgeons level I trauma verification raises hospital performance and improves patient outcome. J Trauma. 2001;51(2):294-299; discussion 299-300.

5. Maggio PM, Brundage SI, Hernandez-Boussard T, Spain DA. Commitment to COT verification improves patient outcomes and financial performance. J Trauma. 2009;67(1):190-194; discussion 194-195.

6. MacKenzie EJ, Rivara FP, Jurkovich GJ, et al. A national evaluation of the effect of trauma-center care on mortality. N Engl J Med. 2006;354(4):366-78.

7. Boyd DR, Lowe RJ, Baker RJ, Nyhus LM. Trauma registry. New computer method for multifactorial evaluation of a major health problem. JAMA. 1973;223(4):422-8.

8. Hospital and prehospital resources for optimal care of the injured patient. Committee on Trauma of the American College of Surgeons. Bull Am Coll Surg. 1986;71(10):4-23.

9. Boyd CR, Tolson MA, Copes WS. Evaluating trauma care: the TRISS method. Trauma Score and the Injury Severity Score. J Trauma. 1987;27(4):370-8.

10. Champion HR, Copes WS, Sacco WJ, et al. The Major Trauma Outcome Study: establishing national norms for trauma care. J Trauma. 1990;30(11):1356-65.

11. Cohen ME, Ko CY, Bilimoria KY, et al. Optimizing ACS NSQIP modeling for evaluation of surgical quality and risk: patient risk adjustment, procedure mix adjustment, shrinkage adjustment, and surgical focus. J Am Coll Surg. 2013;217(2):336-346.e331.

12. Cohen ME, Liu Y, Ko CY, Hall BL. Improved surgical outcomes for ACS NSQIP hospitals over time: evaluation of hospital cohorts with up to 8 years of participation. Ann Surg. 2016;263(2):267-73.

13. Mann NC, Guice K, Cassidy L, Wright D, Koury J. Are statewide trauma registries comparable? Reaching for a national trauma dataset. Acad Emerg Med Off J Soc Acad Emerg Med. 2006;13(9):946-53.

14. What Is the NTDS? 2017; https://www.facs.org/quality-programs/ trauma/ntdb/ntds/about-ntds. Accessed Jan 222018.

15.• Shafi S, Nathens AB, Parks J, Cryer HM, Fildes JJ, Gentilello LM. Trauma quality improvement using risk-adjusted outcomes. J Trauma. 2008;64(3):599-604. discussion 604-596. This citation highlights the variation in outcomes in ACS verified trauma centers, suggesting that the process of verification alone to confirm structures and processes of care does not assure consistent outcome.

16. Hemmila MR, Nathens AB, Shafi S, Calland JF, Clark DE, Cryer HG, et al. The Trauma Quality Improvement Program: pilot study 
and initial demonstration of feasibility. J Trauma. 2010;68(2):25362.

17. Hemmila MR, Cain-Nielsen AH, Wahl WL, Vander Kolk WE, Jakubus JL, Mikhail JN, et al. Regional collaborative quality improvement for trauma reduces complications and costs. J Trauma Acute Care Surg. 2015;78(1):78-87. This citation provides insights into the impact of a regional collaborative on accelerating performance improvement related to trauma.

18. National Trauma Data Standard Data Dictionary. 2018; https:// www.facs.org/quality-programs/trauma/ntdb/ntds/data-dictionary. Accessed December 27th 2017.

19. Kilgo PD, Osler TM, Meredith W. The worst injury predicts mortality outcome the best: rethinking the role of multiple injuries in trauma outcome scoring. J Trauma. 2003;55(4):599-606. discussion 606-597

20. Haider AH, Saleem T, Leow JJ, Villegas CV, Kisat M, Schneider EB, et al. Influence of the National Trauma Data Bank on the study of trauma outcomes: is it time to set research best practices to further enhance its impact? J Am Coll Surg. 2012;214(5):756-68.

21.• Newgard CD, Fildes JJ, Wu L, Hemmila MR, Burd RS, Neal M, et al. Methodology and analytic rationale for the American College of Surgeons Trauma Quality Improvement Program. J Am Coll
Surg. 2013;216(1):147-57. This citation provides the methodology that supports risk adjustment for ACS TQIP.

22. Hemmila MR, Jakubus JL. Trauma quality improvement. Crit Care Clin. 2017;33(1):193-212.

23. Byrne JP, Nathens AB, Gomez D, Pincus D, Jenkinson RJ. Timing of femoral shaft fracture fixation following major trauma: a retrospective cohort study of United States trauma centers. PLoS Med. 2017;14(7):e1002336.

24. Guillamondegui OD, Gunter OL, Hines L, et al. Using the National Surgical Quality Improvement Program and the Tennessee Surgical Quality Collaborative to improve surgical outcomes. J Am Coll Surg. 2012;214(4):709-14. discussion 714-706

25. Benjamin E, Recinos G, Aiolfi A, Inaba K, Demetriades D. Pharmacological thromboembolic prophylaxis in traumatic brain injuries: low molecular weight heparin is superior to unfractionated heparin. Ann Surg. 2017;266(3):463-9.

26. Scarborough JE, Ingraham AM, Liepert AE, Jung HS, O'Rourke AP, Agarwal SK. Nonoperative management is as effective as immediate splenectomy for adult patients with high-grade blunt splenic injury. J Am Coll Surg. 2016;223(2):249-58.

27. Using the Surgeon Specific Registry for CMS MIPS. 2017; https:// www.facs.org/quality-programs/ssr/mips. Accessed January 312018. 